\title{
Changes in vasoactive intestinal peptide, pituitary adenylate cyclase-activating polypeptide and neuropeptide Y-ergic structures of the enteric nervous system in the carcinoma of the human large intestine
}

\author{
Janusz Godlewski' ${ }^{1}$, Ireneusz Miroslaw Lakomy² \\ ${ }^{1}$ Department of Human Histology and Embryology, Faculty of Medicine Sciences, University of Warmia \\ and Mazury in Olsztyn, Poland \\ ${ }^{2}$ Division of Animal Anatomy, Department of Functional Morphology, Faculty of Veterinary Medicine, \\ University of Warmia and Mazury in Olsztyn, Poland
}

\begin{abstract}
This investigation was aimed at immunohistochemical analysis of potential changes in the enteric nervous system caused by cancer of the large intestine. In this purpose, neurons and nerve fibers of intestinal plexuses containing neuropeptides: vasoactive intestinal peptide (VIP), pituitary adenylate cyclase-activating polypeptide (PACAP) and neuropeptide Y (NPY), in pathologically changed part of the large intestine were microscpically observed and compared. Samples were taken from patients operated due to cancer of the sigmoid colon and rectum. The number of neurons and density of nerve fibres containing neuropeptides found in sections with cancer tissues were compared to those observed in sections from the uninvolved intestinal wall. Changes relating to reductions in the number of NPY-ergic neurons and density of nerve fibres in submucous and myenteric plexuses in the sections with cancer tissues (pathological sections) were statistically significant. A statistically similar presence of VIP-ergic and PACAP-ergic neurons in the submucosal and myenteric plexuses was observed in both the pathological and control sections. On the other hand, in the pathological sections, VIP-ergic nerve fibres in the myenteric plexuses and PACAP-ergic nerve fibres in the submucosal and myenteric plexuses were found to be less dense. Analysis revealed changes in pathologically affected part of the large intestine may caused disruption of proper intestinal function. Observed changes in the neural elements which are responsible for relaxation of the intestine may suggest dysfunction in the innervation of this part of the colon.
\end{abstract}

Key words: enteric nervous system, neuropeptides, carcinoma of the large intestine

\section{Introduction}

In physiological conditions, within components of the enteric nervous system supplying the human large intestine, the presence of the following neuropeptides has been found: vasoactive intestinal peptide (VIP), neuropeptide Y (NPY) and pituitary adenylate cyclaseactivating polypeptide (PACAP) [1-5]. It is known that these neuropeptides are neurotransmitters and neuromodulators of the enteric nervous system. The VIPergic neurons of the submucosal plexuses have influence of intestinal secretions and VIP-ergic neurons of

Correspondence: J. Godlewski, 10-628 Olsztyn, Bankowców Str. 35, Poland; tel.: (+48) 698694528,

e-mail: janusz350@poczta.onet.pl the myenteric plexuses cause relaxation of the intestine [6]. It has also been shown that PACAP is a neurotransmitter suppressing the contraction of the intestinal muscle, and in the region of the mucous membrane it cause increases of intestinal secretion [7]. It is also known that NPY inhibits contraction of the intestinal muscle, probably by suppressing the cholinergic transmission and also in the intestinal wall there are postganglionic nerve fibres containing NPY which innervate the submucosal arterioles, producing their constriction [8-10]. Investigations of the enteric nervous system in inflammatory diseases of the large intestine have shown morphological changes in this system. These changes are mostly related with increase, or decrease the number of neurons and density of nerve fibres containing neuropeptides [11-16]. 
Table 1. List of primary antibodies and secondary reagents used in this study.

\begin{tabular}{|c|c|c|c|c|}
\hline Antigen & Code & Species of origin & Dilution & Source \\
\hline \multicolumn{5}{|c|}{ Primary antiscra } \\
\hline $\mathrm{PGP}-9,5$ & $13 \mathrm{C} 4$ & mousc & 1 in 2000 & Biogenesis, UK \\
\hline NPY & RPN 1702 & rabbit & 1 in 5000 & Amersham, UK \\
\hline$P \wedge C \wedge P$ & IHC 8922 & rabbit & 1 in 10000 & Peninsula I aborat.Inc. US $\Lambda$ \\
\hline VI P & V-3508 & rabbit & 1 in 600 & Sigma, US $\Lambda$ \\
\hline \multicolumn{5}{|c|}{ Secondary antisera } \\
\hline \multicolumn{3}{|c|}{ FTTC-conjugated goat anti-mouse $\operatorname{IgG}$} & 1 in 400 & Cappel, USA \\
\hline \multicolumn{3}{|c|}{ Biotinylated goat anti-rabbit $\lg G$} & 1 in 400 & Cappel, USA \\
\hline \multicolumn{3}{|c|}{ Streptavidin-conjugated CY 3} & 1 in 3000 & Jackson Immun. Lab., USA \\
\hline
\end{tabular}

As yet there is no data in the literature dealing with the problem of changes in the innervation of human organs affected by cancer. The presence of nerve fibres containing GAL, SP and NPY has been confirmed only in cancerous tumour of the esophagus and stomach cardia [17]. The only publication presenting changes in the density of nerve fibres in the circular muscle of the large intestine was based on studies on laboratory animals with colon cancer [18].

The study of the innervation of human colon cancer were concerned with analysis of the innervation of blood vessels adjacent to the tumour [19]. Similar observations have been made concerning the colorectal liver metastases, and the presence of this innervation were not observed [20]. It seems that a description of characteristics of morphological changes in the nervous system supplying the large intestine wall in patients with carcinoma of the sigmoid colon and rectum may contribute to mechanism of the symptoms from which the patients are suffering. In view of the points presented above it was decided that this study should deal with localisation and morphological comparison of VIPergic, PACAP-ergic and NPY-ergic neurons and nerve fibres of the enteric nervous system in the wall of the sigmoid colon and rectum with cancerous tumour, between normal and pathologically changed tissues.

\section{Material and methods}

Tissue samples. Samples for this study were taken from postoperative material originating from patients undergoing operations for carcinoma of the large intestine. Material was collected from 15 patients (nine women and six men), of the average age 63.0 years, (range 41-78). Patients in a generally good state of health were qualified for the study, had no evidence of bowel obstruction or other colonic disease. Patients undergoing pre-operative radiotherapy were excluded.

Immunohistochemistry. Two small samples comprising all layers of the intestine wall were taken from the post-operative material. One sample was taken from the macroscopically unchanged part of the intestine at a minimum distance of $5 \mathrm{~cm}$ from the tumour; the second one was taken from the margin of the tumour. The samples were fixed for two hours in $4 \%$ buffered paraformaldehyde solution, rinsed for 24 hours in phosphate buffer and stored in $18 \%$ buffered sucrose solution until further processing. Cryostat sections $(10 \mu \mathrm{m})$ were double-labelled immunohistochemically as described previously [21] for protein gene product-9.5 (PGP-9,5), a marker of nerve structures, and for one of the neuropeptides under study (Table 1).

The labelled sections were studied using a fluorescent microscope (Axiophot Zeiss) and a confocal laser microscope (Bio-Rad Microradiance MR2) equipped with epiillumination and appropriate filter set for fluorescein isothiocyanate (FITC) or Texas Red. Expression of two fluorescent levels was examined by interchanging filters. The images were scanned and then superimposed using appropriate programs (LaserSharp 2000 v. 3.1, Bio-Rad; LaserPix v. 4.0013 Media, Cybernetics L.P.)

A preabsorbtion test was carried out to study the specifity of antisera used and no staining was observed in control sections incubated with antisera preabsorbed with corresponding peptides. Additional negative controls involved the omission and replacement of all primary antisera by non-immune sera.

The number of neurons containing particular examinated substances in the sections from cancer tissues and in the control sections was determined. In this purpose, the number of neurons present in particular plexuses in sections of each part of the intestine was counted. Neurons containing particular labelled neuropeptides were counted in amount at least 400 positive PGP-9.5 neurons.

An analysis of the number of nerve fibres was also carried out. Approximate quantites were assessed using the following scale: $0-$ no fibres, $(+)$ low density of fibres, $(++)$ medium density of fibres, $(+++)$ high density of fibres.

On the basis of initial microscopic observations, only sections were examinated in which the neoplastic tissues were observed and cancerous tumor destroyed the mucous membrane and the submucous tissue. In these sections, the submucous plexuses were visible and the linear structure of the myenteric plexuses was preserved.

Ethical issues. The study was approved by Local Bioethical Commission permit No. 107/2004/II, Warmia and Mazury District Medical Association, Poland.

Statistical analysis. The data obtained were statistically analysed with the Mann and Whitney nonparametric U-test. Comparison of the density of the nerve fibres in the plexuses in the control and pathological sections was carried out using the Kendall $\tau$ rank correlation coefficient $[22,23]$. 
Table 2. Percentage of VIP, PACAP and NPY- ergic neurons found in the submucous plexus in control and pathological sections.

\begin{tabular}{|c|c|c|c|c|c|}
\hline & \multicolumn{2}{|c|}{ Control sections } & \multicolumn{3}{|c|}{ Pathological sections } \\
\hline & $\begin{array}{l}\text { mean percentage of } \\
\text { ncurons }\end{array}$ & $\begin{array}{c}\text { standard deviation } \\
\text { in } \%\end{array}$ & $\begin{array}{l}\text { mean percentage of } \\
\text { ncurons }\end{array}$ & $\begin{array}{c}\text { standard deviation } \\
\text { in } \%\end{array}$ & $\begin{array}{l}\text { level of statistic. significance } \\
\text { at } \mathrm{p} \leq 0.05\end{array}$ \\
\hline VIP & 56.82 & 15.14 & 51.01 & 20.07 & 0.42668 \\
\hline$P \wedge C \wedge P$ & 45.61 & 12.78 & 36.70 & 8.90 & 0.061236 \\
\hline NPY & 36.92 & 9.12 & 16.58 & 8.15 & 0.000057 \\
\hline
\end{tabular}

Table 3. Percentage of VIP, PACAP and NPY- ergic neurons found in the myenteric plexus in control and pathological sections.

\begin{tabular}{|l|c|c|c|c|c|}
\hline \multirow{2}{*}{} & \multicolumn{2}{|c|}{ Control sections } & \multicolumn{3}{c|}{ Pathological sections } \\
\cline { 2 - 6 } & $\begin{array}{c}\text { mean percentage of } \\
\text { neurons }\end{array}$ & $\begin{array}{c}\text { standard deviation } \\
\text { in } \%\end{array}$ & $\begin{array}{c}\text { mean percentage of } \\
\text { neurons }\end{array}$ & $\begin{array}{c}\text { standard deviation } \\
\text { in } \%\end{array}$ & $\begin{array}{c}\text { level of statistic. significance at } \\
\text { p } \leq 0.05\end{array}$ \\
\hline VIP & 36.68 & 15.01 & 43.82 & 17.83 & 0.29313 \\
\hline PACAP & 32.61 & 10.76 & 29.86 & 10.90 & 0.270217 \\
\hline NPY & 42.09 & 6.94 & 25.20 & 10.39 & 0.000365 \\
\hline
\end{tabular}

\section{Results}

The statistical analysis of the present study allowed to resume potential changes in number of neurons and density of nerves fibres containing particular neuropeptides. Comparison of mean percentage of NPYergic neurons in the submucosus plexuses in pathological sections with mean percentage of appreciate neurons in control sections showed statistical significant difference $(p \leq 0.05)$ in presence of two investigated group of neurons. A decrease from $36.92 \%$ to $16.58 \%$ of mean percentage of NPY-ergic neurons in the submucosus plexuses was noted.

However, the statistically similar mean percentage of VIP-ergic neurons, $56.82 \%$ and $51.01 \%$, as well as PACAP-ergic neurons, 45.61 and $36.70 \%$, respectively in the submucosus plexuses was observed. In the myenteric plexus, the statistical significant reduction of mean percentage of NPY-ergic neurons was from $42.09 \%$ in control sections to $25.20 \%$ in pathological sections. Changes of mean percentage of VIP-ergic neurons in the myenteric plexus was statistical insignificant, $36.68 \%$ to $43.82 \%$, respectively. Mean percentage of PACAP-ergic neurons was similar, $32.61 \%$ to $29.86 \%$ in compared groups respectively. The changes in density of nerve fibres containing investigated neuropeptides in both submucosus and the myenteric plexuses were more considerable than the presented above changes of mean percentages of the neurons. A significant decrease in density of PACAP-ergic and NPY-ergic nerve fibres was founded in pathological sections in submucosus and myenteric plexuses respectively and VIP-ergic nerve fibres in the myenteric plexus. However, a decrease density in the number of the VIP-ergic nerve fibres in submucosus plexuses of pathological sections was observed but statistically insignificant. (Tables 2 and 3, Fig. 5 and 6).

\section{Discussion}

The results of this study provide evidence of enteric nervous system state in colon cancer invasion. Changes in neurons and nerve fibres containing investigated neuropeptides located close to cancer tissue were observed. These changes and lack of neural elements in solid cancer tissue may suggest dysfunction of innervation of this and impair part of the colon. It also may caused disruption of proper colon function and may be responsible for some of symptoms due with colorectal cancer invasion.

Anatomical studies on the regular innervation of the intestine in humans have revealed the presence of VIPergic neurons in submucous plexuses and myenteric plexuses of the small and large intestine [2-4,24]. Similar studies carried out on animals have shown also the presence of VIP-ergic neurons in both the small and in the large intestine [25-28]. As mentioned previously, studies on the enteric nervous system of the large intestine with cancer were performed only in relation to changes in the number of neurons and nerve fibres containing VIP in the large intestine of the rat. In these studies, an increase in the density of VIP-ergic fibres in myenteric plexuses of the large intestine with cancer in comparison to the control material has been observed [18]. Studies published so far dealing with changes in the enteric nervous system of the human large intestine were related to other pathological states, mostly inflammatory processes. It has appeared that the results of these studies are often contradictory. Studies relating to Crohn's disease shoud be mentioned, and in this disease 


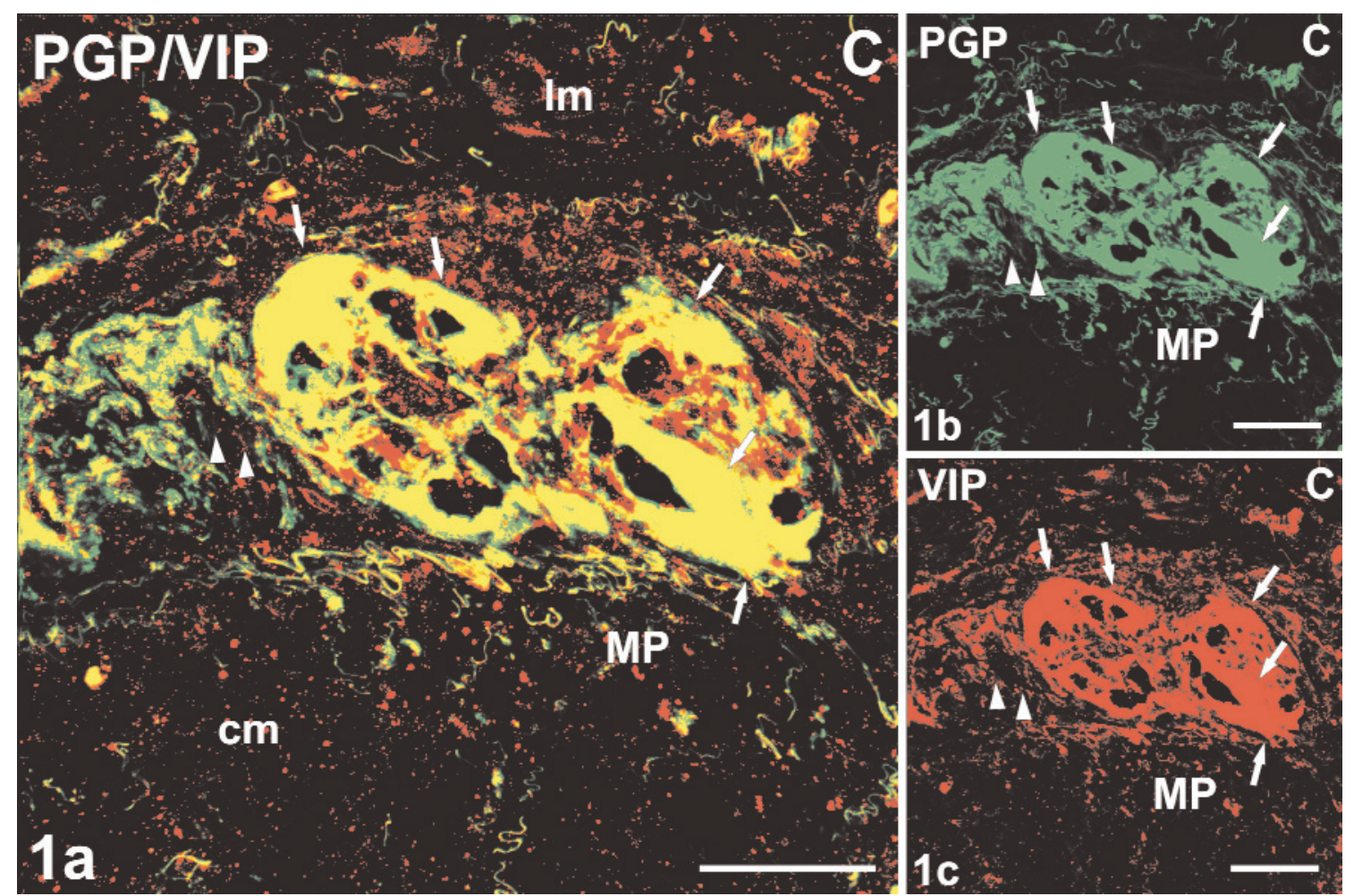

Fig. 1. The myenteric plexus (MP) in a control section. Confocal laser scaning microscope (CLSM) image showing neurons expressing PGP-9.5 (b) and VIP (c). These images were superimposed (a), double labelled (PGP-9.5 and VIP-positive) neurons are yellow. Numerous neurons are visible (arrows) and a dense network of nerve fibres (spearheads) is present. The majority of the neurons and nerve fibres in this plexus were VIP-positive. Bar $=60 \mu \mathrm{m}$.

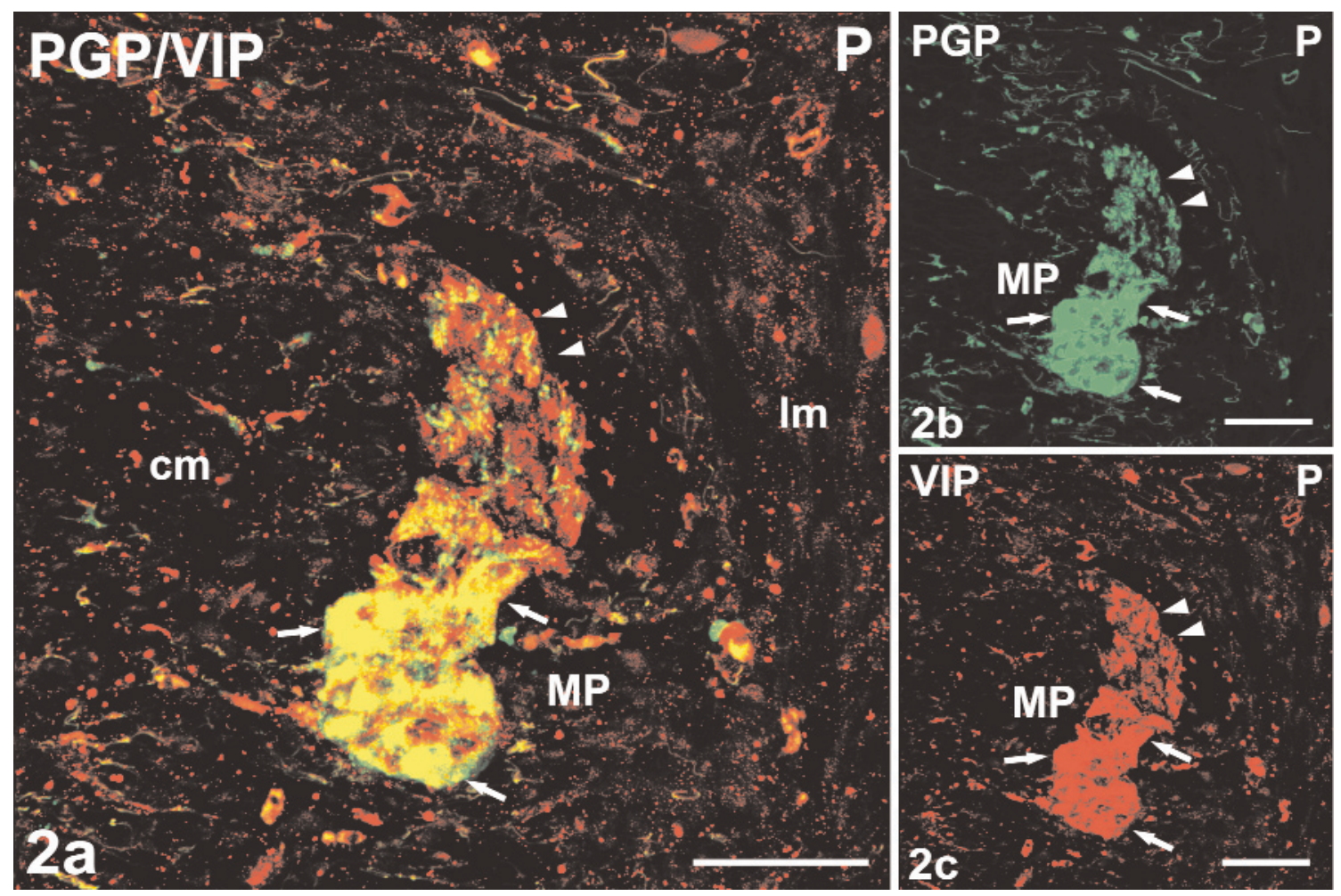

Fig. 2. The myenteric plexus (MP) in a pathological section. CLSM image showing the distribution of neurons expressing PGP-9.5 (b) and VIP (c). These images were superimposed (a), double labelled (PGP-9.5 and VIP-positive) neurons are yellow. Neurons (arrows) and nerve fibres (spearheads) in the MP. The majority of the neurons are VIP-positive; the nerve fibres are of medium density. The difference in size (smaller) and shape of neurons in this plexus in comparison to that shown above (a) is noticeable. The distribution of the nerve fibres is also different in this pathological sections. $\mathrm{Bar}=60 \mu \mathrm{m}$. 


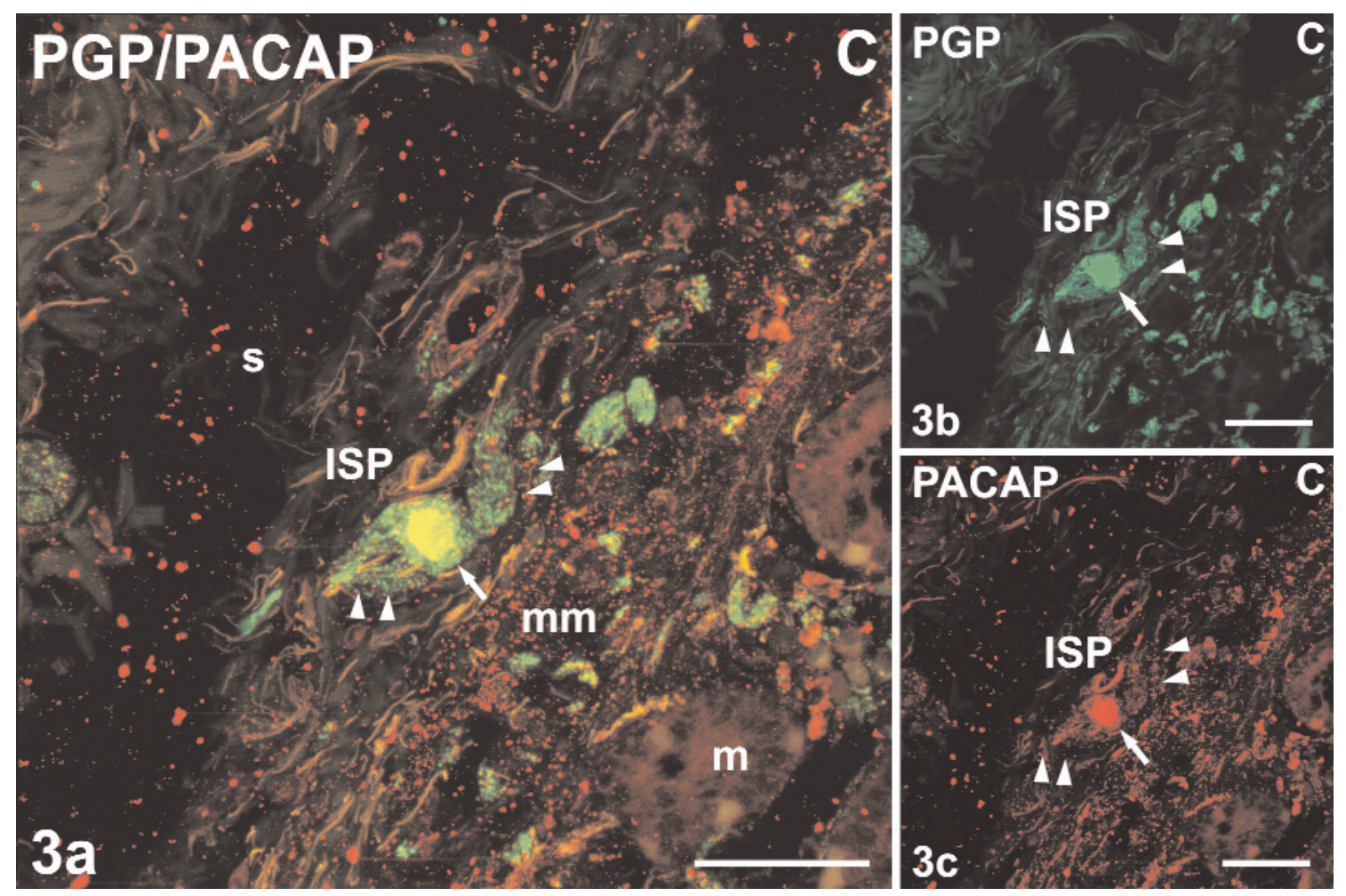

Fig. 3. The inner submucosal plexus (ISP) in a control section. CLSM image showing the distribution of neurons expressing PGP-9.5 (b) and PACAP (c). These images were superimposed (a), double labelled (PGP-9.5 and PACAP-positive) neurons are yellow. Perikarya (arrow) and nerve fibres (spearheads) are visible and form ISP. Bar $=60 \mu \mathrm{m}$.

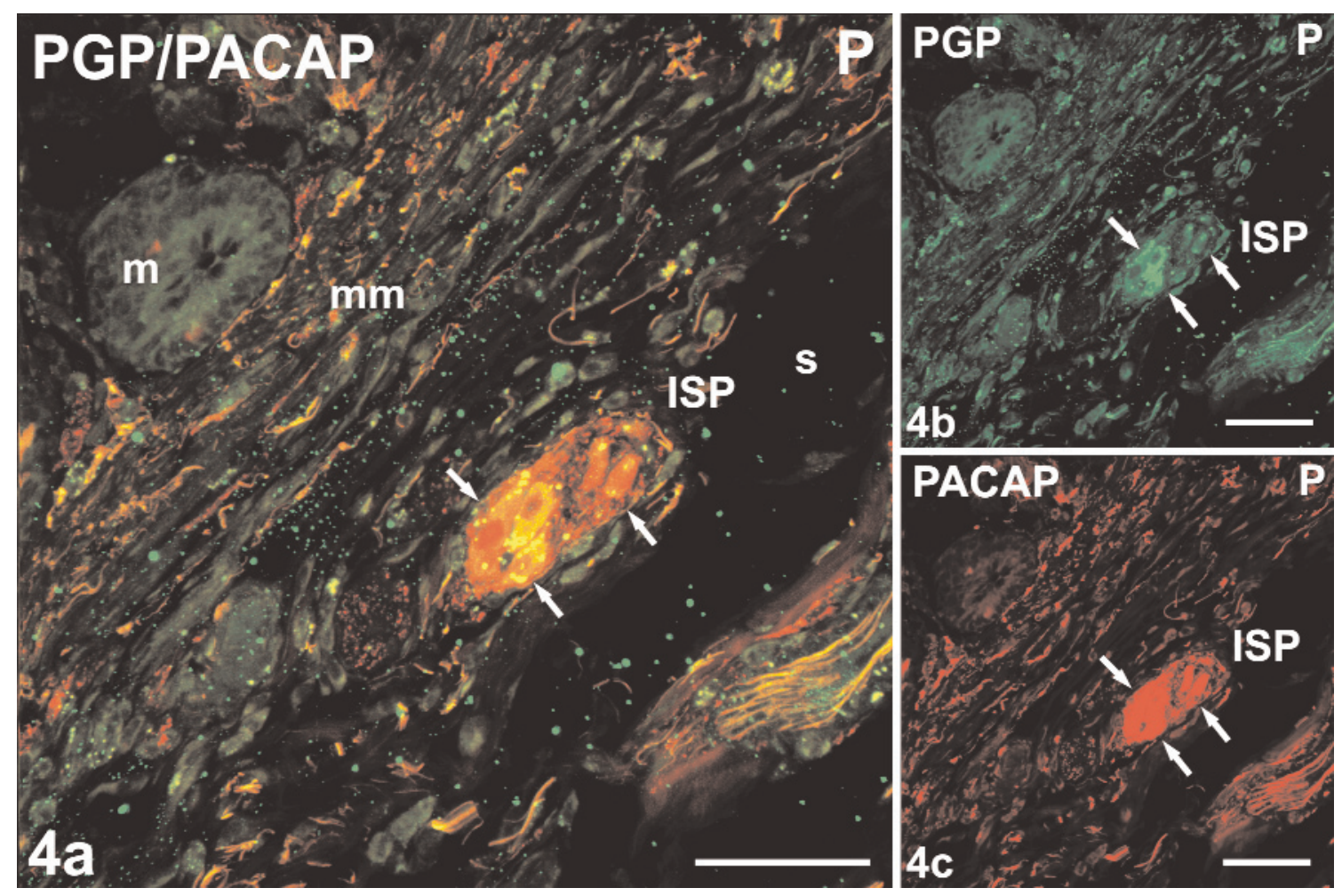

Fig. 4. The inner submucosal plexus (ISP) in a pathological section. CLSM image showing the distribution of neurons expressing PGP9.5 (b) and PACAP (c). These images were superimposed (a), double labelled (PGP-9.5 and PACAP-positive) neurons are yellow. Neurons (arrows) are visible in the ISP. The majority of the neurons were PACAP-positive (arrows). Note the small number of nerve fibres in this plexus. Bar $=60 \mu \mathrm{m}$. 


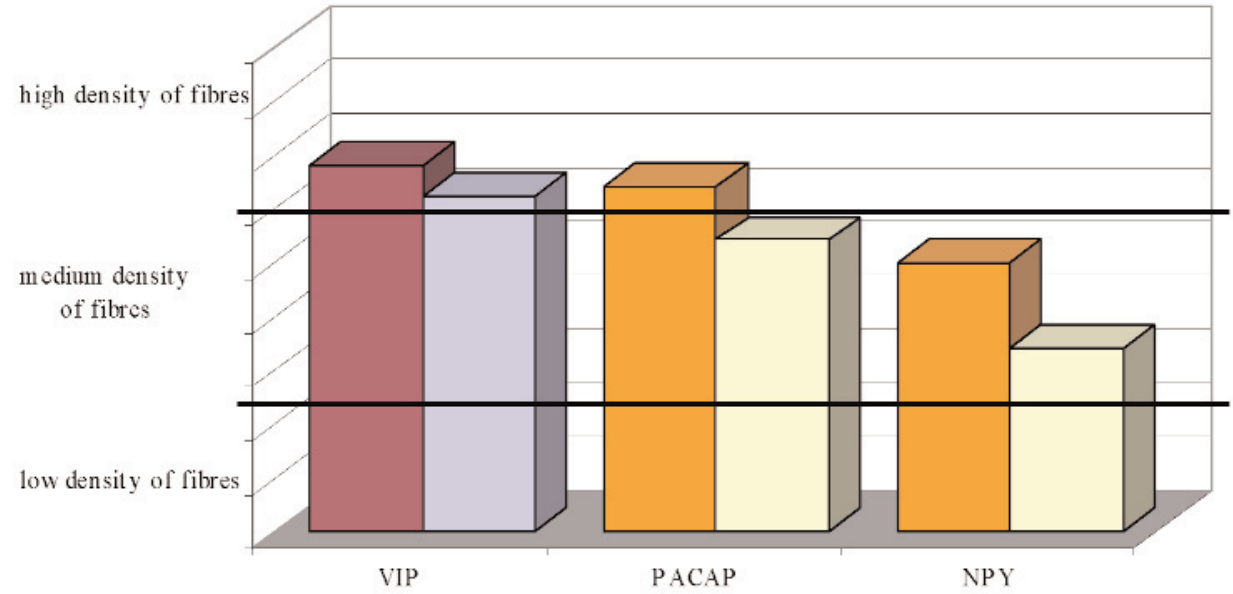

Simillar density of fibres

Observed changes in density of libres

Control sections

$\square$ Pathological sections

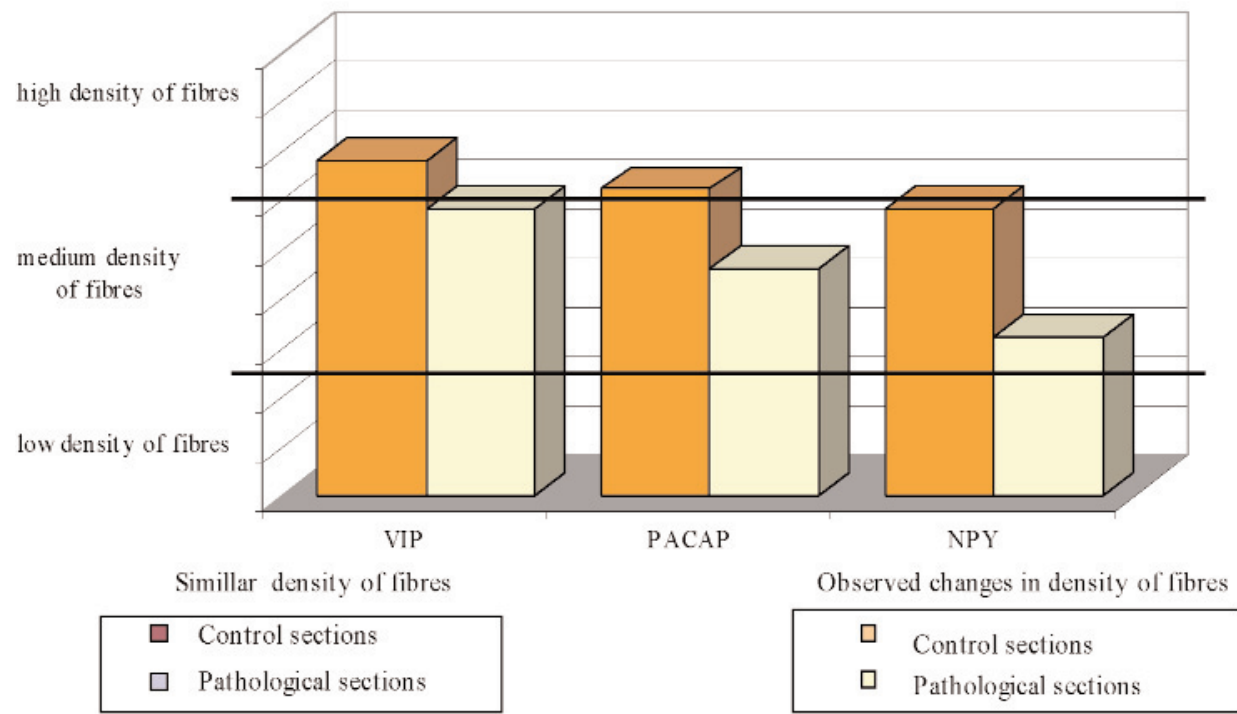

Fig. 5. Changes in the density of nerve fibers in submucous plexuses in control and pathological sections. there is an increase in the density of nerve elements containing VIP in the wall of the small and the large intestine $[11,13]$. On the other hand, observations related to the same disease suggest that there are no similar changes in the density of nerve elements containing VIP in the layers of the intestinal wall [29]. Results of other studies on Crohn's disease are completely different. A reduction in VIP-ergic nerve fibres and VIP concentrations has also been observed in ulcerative colitis $[12,30]$. Post radiation changes of the large intestine, after neoadjuvant radiotherapy, consist of, among others, a decrease, in the number of VIP-ergic nerve fibres in the wall of the intestine [31]. Experimental studies carried out on animals confirm the existence of changes in the innervation of the large intestine during inflam- mation processes. In experimental infection of pigs with the Schistosoma japonicum parasite, a reduction in the number of neurons and the density of VIP-containing nerve fibres in the large intestine was found. This reduction in VIP-ergic elements, to the point where they were completely absent, was accompanied by necrotic and degenerative changes in the wall of the large intestine [32]. Analysis of changes in the number of VIP-ergic nerve elements is difficult due to the different phasing of the state of inflammation of the intestine. The earlier fall in the number of VIP-positive nerve fibres in the large intestinal wall of the rat, and next a later increase in their number have been observed [33]. The data given above indicate that the problem dealing with changes in the quantity of VIP in 
nerve elements supplying the large intestinal wall in various pathological states has not been definitively resolved; in this connection, there is also a lack of data relating to changes in the number of VIP-ergic nerve elements in the human intestine undergoing neoplasmal processes. In the present study, the changes of the number VIP-ergic neurons were observed, but these differences were statistically insignificant in the pathological material in comparison to the control tissues. On the other hand a significant decrease was observed in the density of VIP-ergic nerve fibres in the myenteric plexuses in the pathological material. Taking into considerations the fact that the data in the literature are often contradictory, interpretation of the present results is not easy. The decrease, statistically insignificant, in the number of VIP-ergic neurons in submucous plexuses in the cancerous tumour is certainly brought about by the damage to the intestinal wall caused by the tumour. The results of this study indicates that the submucous plexuses are more sensitive to the destruction with pathological processes, what was previously described [32]. Similar results of studies on the decrease in the density of VIP-ergic nerve fibres have been observed in radiation damage in the human intestine [31]. The reduction in the density of VIP-ergic nerve fibres in pathological material in the myenteric plexuses, as shown in this study, may indicate damage by the tumour to the innervation responsible for diastole of the intestine. The results of this study are not in agreement with the results of studies on inflammatory states of the intestine in humans, where an increase in the number of neurons and VIP-ergic nerve fibres has been observed $[11,13]$. This contradiction may indicate that the mechanism for initiation and development of inflammatory and neoplasmal processes are significantly different. In the diseases mentioned above, the state of inflammation was acute and present in a large part, or the whole of the intestine. It is also probable that the reaction mechanism of the enteric nervous system in the course of cancer is different.

The presence of numerous neurons and PACAPergic nerve fibres in submucous plexuses and in the myenteric plexuses of the large intestine wall has been observed in humans and laboratory animals. These neurons have been described as inhibitory motor neurons, suppressing muscular relaxation, and as cholinergic and non-cholinergic interneurons [5,10,34,35]. There is no dates in the literature reporting changes in PACAP-ergic nervous system in the course of cancer of the large intestine in humans. There are also no such studies on animals. The only relevant published study concerns the innervation of the small intestine in Crohn's disease. In this disease, an increase in the number of neurons and the density of PACAP-ergic nerve fibres in myenteric plexuses of the intestine is found [13]. In the present study, a (statistically insignificant) decrease in the number of neurons in both the submucous and myenteric plexuses in relation to the corresponding plexuses in the control tissues has been noted. A significant reduction in the density of nerve fibres in both the submucous and myenteric plexuses of the large intestine was observed in the pathological tissues. The results obtained in this study does not corroborate findings of other studies which have reported an increase in PACAP-ergic elements in the enteric nervous system of the small intestine in Crohn's disease. In these studies, an increase in the number of neurons and PACAP-ergic nerve fibres was apparently connected with the interaction between the enteric nervous system and the immunological system, in inflammatory diseases of the intestine. The present results showing a reduction in the number of PACAPergic neurons may indicate an impairment of relaxation and decreased secretion in the affected part of the intestine.

There are few studies describing NPY-ergic innervation of the human large intestine wall. The presence of NPY-ergic neurons has been found in the myenteric plexus and the presence of a small number of NPYergic nerve fibres has also been observed in the in the submucous and the myenteric plexuses $[1,2,4,36]$. NPY-ergic innervation in animals is better recognised. The presence of NPY-ergic neurons in the region of the submucous plexuses has been confirmed and these nerve cells have been classified as interneurons and cholinergic secretomotoric neurons. Also NPY is present in postganglionic cholinergic vasoconstrictor nerves. Inhibitory motor neurons and cholinergic interneurons have been located in the myenteric plexus in both the small and large intestine of the guinea pig $[10,27,37,38]$.

Studies published so far have shown a lack of changes in NPY-ergic innervation of the large intestine wall in humans in such pathological conditions as: diverticulosis and idiopathic constipation $[2,39]$. On the other hand, some changes have been observed in Crohn's disease; these changes consist of an increase in the number of NPY-ergic neurons and density of NPY-ergic nerve fibres in the myenteric plexus of the small intestine [13]. In the present study, statistically significant reductions in the number of neurons in submucous and myenteric plexuses in pathological sections as compared to such plexuses in the control material were found. A decrease in the density of NPY-positive nerve fibres in both submucous and myenteric plexuses in the pathological material was also observed, which indicates a substantial damage caused by the cancerous tumour to the NPY-ergic parts of the innervation of the large intestine. Results of other studies, as mentioned above, which have shown a lack of changes in NPYergic innervation in other pathologies of the intestine, 
such as diverticulosis, idiopathic constipation or post-radiation enteropathy, or which have revealed an increase in the number of such elements in the small intestine in Crohn's disease, differ from those of the present study. It may be assumed, that significant changes, as observed in this study, in NPY-ergic innervation - which, in the normal state of the intestine produces diastole of the intestinal wall - may cause an increased contraction of the part of the large intestine affected by cancer.

Acknowledgments: The authors wish to thank Mrs. G. Greniuk and Mr. A. Penkowski for technical assistance and Dr E. Wędrowska for the statistical analysis.

\section{References}

[1] Wattchow DA, Furness JB, Costa M. Distribution and coexistence of peptides in nerve fibers of the external muscle of the human gastrointestinal tract. Gastroenterology. 1988;95:32-41.

[ 2] Milner P, Crowe R, Kamm MA, Lennard-Jones JE, Burnstock G. Vasoactive intestinal polypeptide levels in sigmoid colon in idiopathic constipation and diverticular disease. Gastroenterology. 1990;99:666-675.

[ 3] Domoto T, Bishop AE, Oki M, Polak JM. An in vitro study of the projections of enteric vasoactive intestinal polypeptideimmunoreactive neurons in the human colon. Gastroenterology. 1990;98:819-827.

[4] Crowe R, Kamm MA, Burnstock G, Lennard-Jones JE. Peptide-containing neurons in different regions of the submucous plexus of human sigmoid colon. Gastroenterology. 1992;102:461-467.

[5] Sundler F, Ekblad E, Absood A, Hakanson R, Koves K, Arimura A. Pituitary adenylate cyclase activating peptide: a novel vasoactive intestinal peptide-like neuropeptide in the gut. Neuroscience. 1992;46:439-454.

[6] Furness JB, Young HM, Pompolo S, Bornstein JC, Kunze WA, McConalogue K. Plurichemical transmission and chemical coding of neurons in the digestive tract. Gastroenterology. 1995; 108:554-563.

[7] Vaudry D, Gonzalez BJ, Basille M, Yon L, Fournier A, Vaudry H. Pituitary adenylate cyclase-activating polypeptide and its receptors: from structure to functions. Pharmacol Rev. 2000;52:269-324.

[8] Allen JM, Hughes J, Bloom SR. Presence, distribution, and pharmacological effects of neuropeptide $\mathrm{Y}$ in mammalian gastrointestinal tract. Dig Dis Sci.1987; 32:506-512.

[9] Surprenant A. Control of the gastrointestinal tract by enteric neurons. Annu Rev Physiol 1994;56:117-140.

[10] Timmermans JP, Adriaensen D, Cornelissen W, Scheuermann DW. Structural organization and neuropeptide distribution in the mammalian enteric nervous system, with special attention to those components involved in mucosal reflexes. Comp Biochem Physiol A Physiol. 1997;118:331-340.

[11] Bishop AE, Polak JM, Bryant MG, Bloom SR, Hamilton S. Abnormalities of vasoactive intestinal polypeptide-containing nerves in Crohn's disease. Gastroenterology. 1980;79:853860.

[12] Kubota Y, Petras RE, Ottaway CA, Tubbs RR, Farmer RG, Fiocchi C. Colonic vasoactive intestinal peptide nerves in inflammatory bowel disease. Gastroenterology. 1992;102:1242-1251.

[13] Belai A, Boulos PB, Robson T, Burnstock G Neurochemical coding in the small intestine of patients with Crohn's disease. Gut. 1997;40:767-774.
[14] Watanabe T, Kubota Y, Muto T. Substance P containing nerve fibers in ulcerative colitis. Int J Colorectal Dis. 1998;13:6167.

[15] Lomax AE, Fernandez E, Sharkey KA. Plasticity of the enteric nervous system during intestinal inflammation. Neurogastroenterol Motil. 2005;17:4-15.

[16] Łakomy M, Sienkiewicz W, Żmudzki J, Kaleczyc J, Wąsowicz K. Changes in the expression of some neuropeptides in the intestines and nerve ganglia during porcine dysentery. Bull Vet Inst Pulawy. 2005;393-398.

[17] Lu SH, Zhou Y, Que HP, Liu SJ . Peptidergic innervation of human esophageal and cardiac carcinoma. World J Gastroenterol. 2003;9:399-403.

[18] Sitohy B, El Salhy M. Changes in the colonic enteric nervous system in rats with chemically induced colon dysplasia and carcinoma. Acta Oncol. 2002;41:543-549.

[19] Chamary VL, Robson T, Loizidou M, Boulos PB, Burnstock G. Progressive loss of perivascular nerves adjacent to colorectal cancer.Eur J Surg Oncol. 2000;26:588-93

[20] Ashraf S, Crowe R, Loizidou MC, Turmaine M, Taylor I, Burnstock G. The absence of autonomic perivascular nerves in human colorectal liver metastases. $\mathrm{Br} J$ Cancer. 1996;73:349-359.

[21] Pidsudko Z, Kaleczyc J, Majewski M, Lakomy M, Scheuermann DW, Timmermans JP (2001) Differences in the distribution and chemical coding between neurons in the inferior mesenteric ganglion supplying the colon and rectum in the pig. Cell Tissue Res 303:147-158.

[22] Kowal J. Metody statystyczne w badaniach sondażowych rynku. PWN Warszawa; 1998.

[23] Sobczyk M. Statystyka. PWN Warszawa; 2000.

[24] Hens J, Vanderwinden JM, De Laet MH, Scheuermann DW, Timmermans JP. Morphological and neurochemical identification of enteric neurones with mucosal projections in the human small intestine. $J$ Neurochem 2001;76:464-471.

[25] Furness JB, Costa M, Walsh JH. Evidence for and significance of the projection of VIP neurons from the myenteric plexus to the taenia coli in the guinea pig. Gastroenterology. 1981;80:1557-1561.

[26] Costa M, Brookes SJ, Steele PA, Gibbins I, Burcher E, Kandiah CJ. Neurochemical classification of myenteric neurons in the guinea-pig ileum. Neuroscience. 1996;75:949-967.

[27] Lomax AE, Furness JB Neurochemical classification of enteric neurons in the guinea-pig distal colon. Cell Tissue Res. 2000;302:59-72.

[28] Hens J, Gajda M, Scheuermann DW, Adriaensen D, Timmermans JP. The longitudinal smooth muscle layer of the pig small intestine is innervated by both myenteric and submucous neurons. Histochem. Cell Biol. 2002;117:481-492.

[29] Sjolund K, Schaffalitzky OB, Muckadell DE, et al. Peptidecontaining nerve fibres in the gut wall in Crohn's disease. Gut. 1983;24:724-733.

[30] Koch TR, Carney JA, Go VL. Distribution and quantitation of gut neuropeptides in normal intestine and inflammatory bowel diseases. Dig Dis Sci. 1987;32:369-376.

[31] Hockerfelt U, Franzen L, Norrgard O, Forsgren S. Early increase and later decrease in VIP and substance P nerve fiber densities following abdominal radiotherapy: a study on the human colon. Int J Radiat Biol. 2002;78:1045-1053.

[32] Balemba OB, Semuguruka WD, Hay-Schmidt A, Johansen MV, Dantzer V. Vasoactive intestinal peptide and substance Plike immunoreactivities in the enteric nervous system of the pig correlate with the severity of pathological changes induced by Schistosoma japonicum. Int $J$ Parasitol. 2001;31:1503-1514.

[33] Miampamba M, Chery-Croze S, Chayvialle JA. Spinal and intestinal levels of substance $\mathrm{P}$, calcitonin gene-related peptide and vasoactive intestinal polypeptide following perendo- 
scopic injection of formalin in rat colonic wall. Neuropeptides. 1992;22:73-80.

[34] Portbury AL, McConalogue K, Furness JB, Young HM. Distribution of pituitary adenylyl cyclase activating peptide (PACAP) immunoreactivity in neurons of the guinea-pig digestive tract and their projections in the ileum and colon. Cell Tissue Res. 1995;279:385-392.

[35] Hannibal J, Ekblad E, Mulder H, Sundler F, Fahrenkrug J. Pituitary adenylate cyclase activating polypeptide (PACAP) in the gastrointestinal tract of the rat: distribution and effects of capsaicin or denervation. Cell Tissue Res. 1998;291:65-79.

[36] Schemann M, Neunlist M. The human enteric nervous system. Neurogastroenterol Motil. 2004;16 Suppl 1:55-59.
[37] Furness JB, Costa M, Keast JR. Choline acetyltransferaseand peptide immunoreactivity of submucous neurons in the small intestine of the guinea-pig. Cell Tissue Res. 1984;237:329-336.

[38] Keast JR, Furness JB, Costa M. Distribution of certain peptide-containing nerve fibres and endocrine cells in the gastrointestinal mucosa in five mammalian species. J Comp Neurol. 1985;236:403-422.

[39] Koch TR, Carney JA, Go L, Go VL. Idiopathic chronic constipation is associated with decreased colonic vasoactive intestinal peptide. Gastroenterology. 1988a; 94:300-310.

Submitted: 20 September, 2009 Accepted after reviews: 17 March, 2010 